\title{
Heterogeneous Catalyst Based on Phosphine-Containing Organic Polymer for Hydroformylation of Octene-1
}

\author{
D. N. Gorbunov ${ }^{a}, *$ M. V. Nenasheva ${ }^{a}$, R. P. Matsukevich ${ }^{a}$, M. V. Terenina ${ }^{a}$, \\ Yu. S. Kardasheva ${ }^{a}$, and E. A. Karakhanov ${ }^{a}$ \\ ${ }^{a}$ Department of Chemistry, Lomonosov Moscow State University, Moscow, 119992 Russia \\ *e-mail:suskab_91@mail.ru
}

Received November 24, 2020; revised December 5, 2020; accepted January 9, 2021

\begin{abstract}
A phosphine-containing porous polymer (TPDB), and a rhodium catalyst based on it, were synthesized. Proceeding from the relevant TEM, NMR, IR spectroscopy, and XPS data obtained, it was assumed that both the $\mathrm{Rh}(\mathrm{I})$ complexes and the $\mathrm{Rh}(0)$ nanoparticles that are stabilized in the polymer pores act as the catalyst's active phase. The size of the nanoparticles $(2-6 \mathrm{~nm})$ is consistent with that of the polymer pores. The catalyst was tested in a model reaction of octene- 1 hydroformylation at 2.0 $\mathrm{MPa}\left(\mathrm{CO}: \mathrm{H}_{2}=1: 1\right)$ in the temperature range of $60-120^{\circ} \mathrm{C}$. It was demonstrated that the catalyst can be used repeatedly, and its activity remains constant from the third cycle of its use (aldehyde yield about $30 \%$ for $5 \mathrm{~h}$, n/iso 2.5).
\end{abstract}

Keywords: hydroformylation, porous organic polymer, rhodium nanoparticles, rhodium complexes, catalysis, heterogeneous catalyst

DOI: $10.1134 / \mathrm{S} 0965544121040010$

Hydroformylation of unsaturated compounds (i.e., catalytic interaction of olefins with syngas at elevated pressures and temperatures) is one of the most important organic synthesis reactions to obtain aldehydes with various structures [1,2]. Industrial-scale olefin hydroformylation processes utilize homogeneous cobalt-based $\left(140-200^{\circ} \mathrm{C}\right.$, 5.0-30.0 MPa) and rhodium-based $\left(85-130^{\circ} \mathrm{C}, 1.5-\right.$ $5.0 \mathrm{MPa}$ ) catalysts, either in the form of hydridocarbonyls or modified with donor ligands, most often alkyl- or aryl substituted phosphines. However, even if the required levels of substrate conversion rate and reaction selectivity are achieved, the efficiency of the catalyst separation/ recirculation step remains to be improved [3, 4]. The conventional extraction and distillation methods are very complex in terms of engineering design. Moreover, their implementation often leads to the deactivation and loss of the expensive catalyst as a result of the decomposition of the metal complex and the oxidation or destruction of the ligand; as a consequence, a regeneration step is required [5-7]. An alternative method was developed in Germany in $1984[8,9]$. This method involves propylene hydroformylation under two-phase catalysis conditions using a water-soluble catalyst. However, this approach has proved to be applicable only to the hydroformylation of lower olefins because olefins with a chain length above $\mathrm{C}_{6}$ significantly reduce the reaction rate due to their low water solubility [10-13].

The challenge of catalyst separation from the reaction products, regardless of the type of substrate being processed, can be overcome by using heterogeneous catalysts. Considerable experience has been gained in this area. Various approaches to the fixation of the active metal on the surface, in the pores, or inside the structure of the support have been systematized in a number of review papers [14-17]. The main disadvantage of heterogeneous catalysts for liquid-phase hydroformylation is the leaching of active metal particles into the reaction medium, which causes their rapid deactivation and inability to operate continuously. The leaching is associated with a number of causes, in particular the formation of organicsoluble metal hydridocarbonyls, namely $\mathrm{HCo}(\mathrm{CO})_{4}$ or 
$\mathrm{HRh}(\mathrm{CO})_{4}$, under the effects of syngas and elevated temperatures $[18,19]$.

A very promising approach to the creation of heterogeneous hydroformylation catalysts involves the preparation of rhodium catalysts from porous organic polymers. These supports combine the high porosity and high density of ligand fragments with a good resistance to organic media and elevated temperatures. The provision of specific coordination sites in the polymer's structure offers good opportunities for their use in selective synthesis of linear aldehydes or in asymmetric synthesis applications. The available information on the utilization of catalysts based on porous organic polymers in hydroformylation has been systematized in a review paper [20]. The general synthesis method for these polymers comprises the preparation of monomers (specifically, arylphosphine or phosphite derivatives that contain vinyl fragments) followed by their polymerization. The resultant porous materials were treated with rhodium precursors, which made it possible to prepare heterogeneous catalyst samples that exhibited high levels of stability, activity, chemoselectivity, and regioselectivity in the hydroformylation of a number of model substrates [21].

The purpose of this study was to prepare a heterogeneous rhodium catalyst based on a phosphorus-containing porous organic polymer (TPDB) and to examine its activity in the liquid-phase hydroformylation of octene-1 as a model substrate.

\section{EXPERIMENTAL}

We used $\mathrm{FeCl}_{3}$ (Sigma-Aldrich, 99.9\%), $\alpha, \alpha^{\prime}$-dibromop-xylene (Sigma-Aldrich, 98\%), triphenylphosphine (Sigma-Aldrich, 99\%), phenylsilane (Sigma-Aldrich, 96.5\%), and octene-1 (Sigma-Aldrich). The following solvents were used: 1,2-dichloroethane (Acros Organics, 99.8\%), methanol (Acros Organics, 99\%), and toluene (Komponent-Reaktiv, CP grade). The solvents were purified according to standard procedures. Rhodium acetylacetonate dicarbonyl, or $\mathrm{Rh}(\mathrm{acac})(\mathrm{CO})_{2}$, was analyzed by the method described in [22].

The starting materials, the polymeric supports and catalysts based on them, and the reaction products were analyzed by gas-liquid chromatography (GLC), spectrophotometry, IR spectroscopy, solid-state NMR spectroscopy, X-ray photoelectron spectroscopy (XPS), atomic absorption spectroscopy, transmission electron microscopy (TEM), and low-temperature nitrogen adsorption/desorption.
The GLC was performed on a Khromos chromatograph equipped with a flame ionization detector and a $30 \mathrm{~m}$ capillary column (DB-5 phase, programmed heating from 60 to $235^{\circ} \mathrm{C}$ at a rate of $10^{\circ} \mathrm{C} / \mathrm{min}$, helium as a carrier gas). The phosphorus and silicon contents were determined on an Agilent Cary-100 double-beam spectrophotometer. The supports and catalysts were analyzed on a Thermo Scientific Nicolet IR 2000 FT-IR spectrometer. The solidstate ${ }^{1} \mathrm{H},{ }^{31} \mathrm{P}$, and ${ }^{13} \mathrm{C}$ NMR measurements were performed on a BRUKER AVANCE-II $400 \mathrm{WB}$ spectrometer with an operating frequency of 400.13 and $162.0 \mathrm{MHz}$, respectively. The XPS examination was carried out using a RIBER LAS-3000 electron spectrometer equipped with an OPX-150 photoelectron analyzer with retarding potential. Rhodium in the samples was quantified by flame atomic absorption spectroscopy on an AAnalyst 400 spectrometer. The TEM examination was performed on a LEO 912 AB OMEGA microscope (magnification: 80-500 000×; image resolution: $0.20-0.34 \mathrm{~nm}$ ) with an electron beam up to $100 \mathrm{eV}$.

The porous properties were determined on a Micromeritics Gemini VII 2390 (V1.02t) analyzer according to a standard procedure. Prior to testing, the samples were degassed at $120^{\circ} \mathrm{C}$ and $3 \times 10^{-4} \mathrm{MPa}$ for $12 \mathrm{~h}$. The adsorption and desorption isotherms were recorded at $77 \mathrm{~K}$. The porosity was calculated using a standard software package. The specific surface area was determined using a Brunauer-Emmett-Teller (BET) model at a relative partial pressure of $p / p_{0}=0.2$. The total pore volume and pore size distribution were evaluated using a Barrett-Joyner-Halenda (BJH) model at a relative partial pressure of $p / p_{0}=0.95$.

The phosphine-containing porous polymer (TPDB) was synthesized by the alkylation of triphenylphosphine with $\alpha, \alpha^{\prime}$-dibromo- $p$-xylene followed by reduction with phenylsilane (Scheme 1).

A TP(O)DB polymer was prepared (the initial step) similarly to the method described in [23]. However, we used a different reagent mixing sequence to avoid triphenylphosphine quaternization, which took place under the original procedure and made it unnecessarily difficult to implement. Our synthesis procedure was as follows. First, $2.66 \mathrm{~g}$ of $\alpha, \alpha^{\prime}$-dibromo- $p$-xylene was dissolved in $30 \mathrm{~mL}$ of 1,2-dichloroethane in a $250 \mathrm{~mL}$ three-neck flask equipped with a magnetic stirrer and a reflux condenser with a chloro-calcium tube. Then $6.48 \mathrm{~g}$ of anhydrous $\mathrm{FeCl}_{3}$ was added. Next, the contents of the flask were cooled in an ice bath, and a solution of $2.64 \mathrm{~g}$ of triphenylphosphine in 
Scheme 1. Synthesis of phosphine-containing support (TPDB).
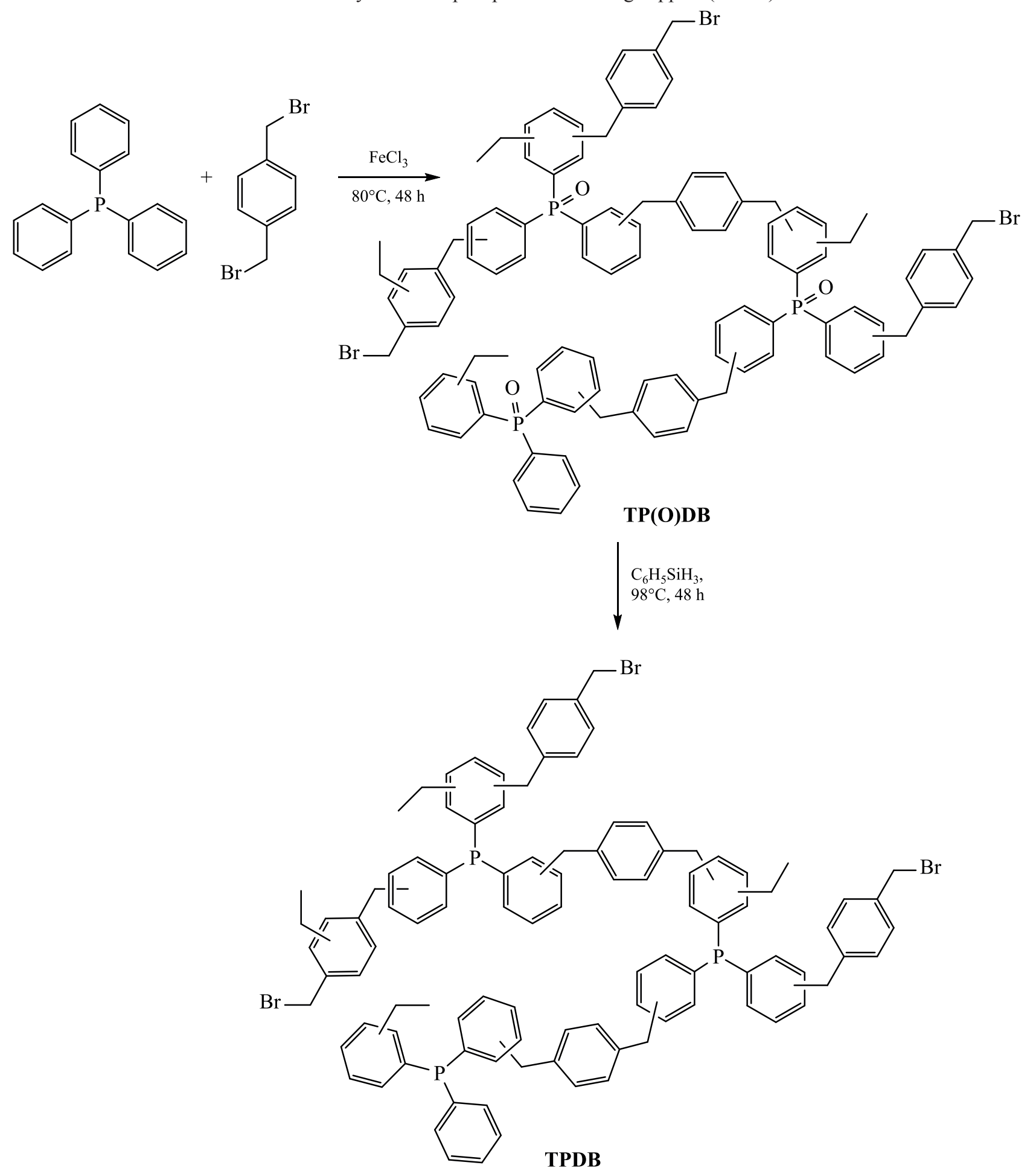

$20 \mathrm{~mL}$ of 1,2-dichloroethane was added. After $10 \mathrm{~min}$, the flask was placed into a silicone oil bath, heated to $45^{\circ} \mathrm{C}$, and stirred for $5 \mathrm{~h}$. Then the flask was further heated to $80^{\circ} \mathrm{C}$, and the reaction was conducted for $48 \mathrm{~h}$. All these steps were carried out in an argon stream.
The product was washed with 1,2-dichloroethane and methanol, and vacuum-dried.

To prepare a phosphine-containing TPDB support, the TP(O)DB polymer was reduced with phenylsilane. For this purpose, $1.5 \mathrm{~g}$ of $\mathrm{TP}(\mathrm{O}) \mathrm{DB}$ was placed into 
a $100 \mathrm{~mL}$ argon-filled round-bottom flask equipped with a magnetic stirrer, and $4.5 \mathrm{~mL}$ of phenylsilane and $10 \mathrm{~mL}$ of toluene were added. The flask, sealed tightly with a plug fitted with a Teflon gasket, was placed into a silicone oil bath. The reaction was carried out at $98^{\circ} \mathrm{C}$ under vigorous stirring for $48 \mathrm{~h}$. The resultant precipitate was dried on a rotary evaporator at $60^{\circ} \mathrm{C}$ for $40 \mathrm{~min}$. The product weighed $2.5 \mathrm{~g}$.

$\mathrm{The} \mathrm{Rh} / \mathrm{TPDB}$ catalyst was synthesized in an inert atmosphere. $300 \mathrm{mg}$ of the polymeric support and $18 \mathrm{mg}$ of $\mathrm{Rh}(\mathrm{acac})(\mathrm{CO})_{2}$ were placed into a $25 \mathrm{~mL}$ argonfilled flask equipped with a magnetic stirrer; then $4 \mathrm{~mL}$ of toluene was poured. The flask was tightly closed with a glass stopper. The mixture was stirred for $5 \mathrm{~h}$, and the resultant precipitate was centrifuged, washed with toluene ( 3 times, $5 \mathrm{~mL}$ each), and vacuum-dried for $1 \mathrm{~h} .243 \mathrm{mg}$ of a light brown Rh/TPDB powder was ultimately obtained.

The hydroformylation reaction in the presence of the heterogeneous $\mathrm{Rh} / \mathrm{TPDB}$ catalyst was carried out in a $25 \mathrm{~mL}$ steel autoclave equipped with a thermostat and a magnetic stirrer. The calculated amounts of catalyst, octene-1, and toluene were placed into the argon-purged autoclave. The reaction occurred under continuous stirring, at pressure of $2.0 \mathrm{MPa}\left(\mathrm{CO}: \mathrm{H}_{2}=1: 1\right)$ and a specific temperature $\left(60-120^{\circ} \mathrm{C}\right)$, for a time period individually determined for each specific experiment. Then the autoclave was cooled to room temperature and depressurized. The catalyst was centrifuged from the reaction mixture and washed with toluene, before being reused in the reaction.

\section{RESULTS AND DISCUSSION}

The low-temperature nitrogen adsorption/desorption of the TP(O)DB sample demonstrates a high specific surface area of the polymer synthesized $\left(590.5 \mathrm{~m}^{2} / \mathrm{g}\right.$, at a pore volume of $0.9 \mathrm{~cm}^{3} / \mathrm{g}$ and an average pore size of $6 \mathrm{~nm}$ ). The adsorption/desorption isotherms (Fig. 1) display a hysteresis loop, which is indicative of a mesoporous structure. On the other hand, the high nitrogen absorption at low pressures, the further gradual increase in this parameter with an increase in $p / p_{0}$, and the abrupt rise in the high pressure region $\left(p / p_{0}=0.8-1.0\right)$, prove the presence of both mesopores and micropores in the polymer.

The TP(O)DB polymer obtained was measured by solid-state ${ }^{1} \mathrm{H},{ }^{13} \mathrm{C}$, and ${ }^{31} \mathrm{P}$ NMR. The ${ }^{1} \mathrm{H}$ NMR spectrum (Fig. 2a) contains overlapping signals at 3.0 and $6.5 \mathrm{ppm}$, which correspond to the hydrogen atoms of the

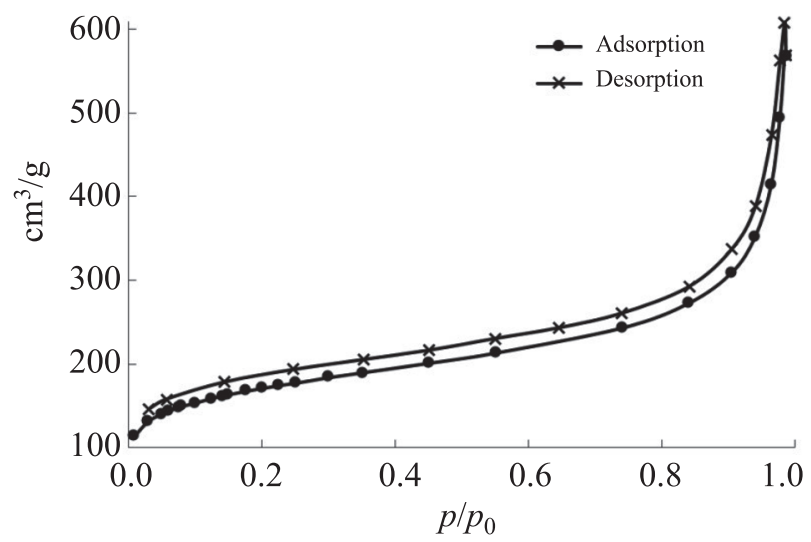

Fig. 1. Low-temperature nitrogen adsorption/desorption isotherms of phosphorus-containing $\mathrm{TP}(\mathrm{O}) \mathrm{DB}$.

polymer's aromatic and aliphatic fragments, respectively. The carbon spectrum (Fig. 2c) displays a broad signal at $131 \mathrm{ppm}$, corresponding to the carbon atoms of the aromatic fragments, as well as signals between 10 $60 \mathrm{ppm}$, typical of the aliphatic carbon atoms connected to the aromatic system. In the ${ }^{31} \mathrm{P}$ NMR spectrum (Fig. 2b) of the TP(O)DB sample, the intense signal at $23 \mathrm{ppm}$ indicates an almost complete oxidation of the triphenylphosphine groups during the synthesis. The interaction with phenylsilane is followed by a partial reduction of phosphine oxide fragments, as indicated by a signal at $-5 \mathrm{ppm}$ that appears in the TPDB spectrum (Fig. 2d). However, the phenylsilane treatment contaminates the sample with silicon compounds, as evidenced both by the elemental analysis data $(2.48 \% \mathrm{Si})$ and by a significant reduction in the surface area (up to $0.03 \mathrm{~m}^{2} / \mathrm{g}$ ). The TEM data show the random porous structure of the support prepared (Figs. 3a, 3b).

Rhodium was applied by interaction between the TPDB polymer and the rhodium acetylacetonate dicarbonyl in toluene. The rhodium content in the Rh/TPDB, quantified by flame atomic absorption spectroscopy, is $1.2 \%$.

Rh3d core level X-ray photoelectron spectrum of the Rh/TPDB sample (Fig. 3d) exhibits signals at $307.3 \mathrm{eV}(5 / 2)$ and $312.1 \mathrm{eV}(3 / 2)$, typical of rhodium in the zero oxidation degree [24] and, thus, indicative of $\mathrm{Rh}(0)$ nanoparticles in the sample. These nanoparticles likely result from rhodium reduction by phenylsilane during the catalyst synthesis, where the rhodium is retained in the support's pores. At the same time, the $308.5 \mathrm{eV}(5 / 2)$ and $313.2 \mathrm{eV}(3 / 2)$ signals, as well as the $309.2 \mathrm{eV}(5 / 2)$ and $314.0 \mathrm{eV}(3 / 2)$ signals, are typical of $\mathrm{Rh}(+1)$ complexes [25]. The Rh/TPDB micrographs 

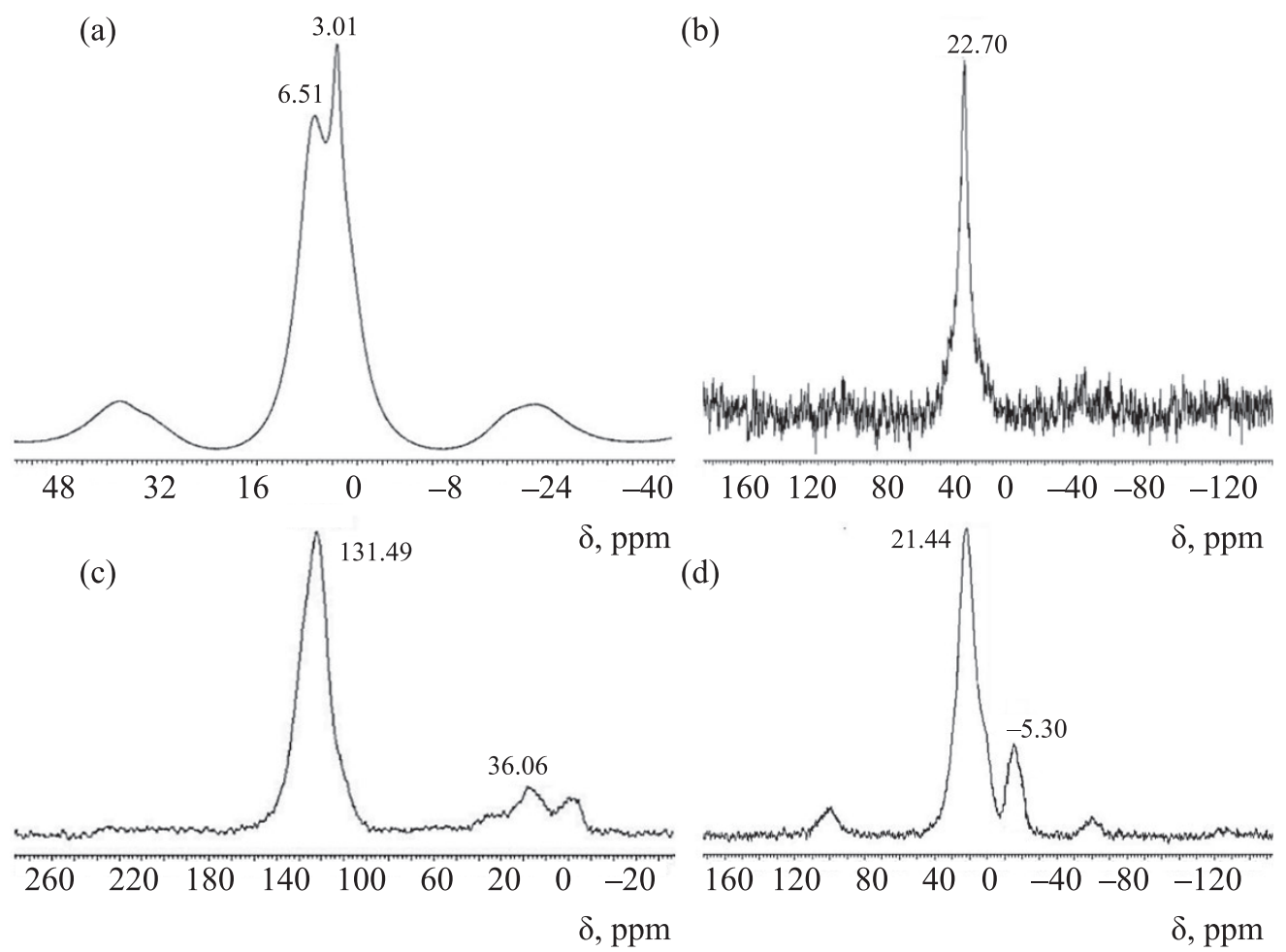

Fig. 2. (a) ${ }^{1} \mathrm{H}$ NMR spectrum of TP(O)DB; (b) ${ }^{31} \mathrm{P}$ NMR spectrum of TP(O)DB; (c) ${ }^{13} \mathrm{C}$ NMR spectrum of TP(O)DB; and (d) ${ }^{31} \mathrm{P}$ NMR spectrum of TPDB.

(Figs. 3a, 3b) can serve to identify spherical rhodium nanoparticles with an average diameter of $4 \mathrm{~nm}$.

The TP(O)DB's IR spectrum contains absorption bands typical of the $\mathrm{C}-\mathrm{H}(912,870,742,721$, and $\left.692 \mathrm{~cm}^{-1}\right)$ and $-\mathrm{C}=\mathrm{C}-\left(1437-1612 \mathrm{~cm}^{-1}\right)$ bonds of the aromatic ring, as well as $\mathrm{P}-\mathrm{C}=\mathrm{C}\left(1683 \mathrm{~cm}^{-1}\right)$ and $\mathrm{Ph}_{3} \mathrm{P}=\mathrm{O}\left(1186 \mathrm{~cm}^{-1}\right)$ [26]. The TPDB spectrum displays the appearance of absorption bands attributable to the valence vibrations of $\mathrm{Si}-\mathrm{H}\left(2158 \mathrm{~cm}^{-1}\right)$ and $\mathrm{Si}-\mathrm{O}-\mathrm{Si}$ (1000-1100 and $814 \mathrm{~cm}^{-1}$ ) [26, 27], which indicate the contamination of the sample with silicon compounds. The application of rhodium to the polymer results in the appearance of absorption bands near $2061 \mathrm{~cm}^{-1}$ and near $1993 \mathrm{~cm}^{-1}$ (corresponding to the Rh-CO vibrations), as well as signals in the range of $1635-1652 \mathrm{~cm}^{-1}$ (evidence of an $\mathrm{acac}^{-}$anion in the coordination environment of rhodium) [28]. Rhodium nanoparticles of different sizes ( 2 to $6 \mathrm{~nm}$, depending on the size of the pores in which they are located) are fixed in the polymer matrix. The polymer structure also contains rhodium complexes in which $\mathrm{Rh}(+1)$ is bonded to triphenylphosphine ligand, carbon monoxide, and an $\mathrm{acac}^{-}$ion.

The catalytic activity of the resultant heterogeneous $\mathrm{Rh} / \mathrm{TPDB}$ catalyst was examined in a model reaction of octene-1 hydroformylation. Although the catalyst demonstrated sufficiently high activity in the first catalytic experiment (Cycle 1), its activity noticeably declined during Cycle 2. This is most probably associated with the partial leaching, into the solution, of the rhodium acetylacetonate dicarbonyl that was sorbed but not bonded chemically to the polymer fragments. As a consequence, the reaction occurred not only on the active sites of the heterogeneous catalyst, but also on $\mathrm{HRh}(\mathrm{CO})_{4}$ (rhodium hydridocarbonyl) formed from $\mathrm{Rh}(\mathrm{acac})(\mathrm{CO})_{2}$ in the syngas atmosphere, thus leading to a higher aldehyde yield than in the subsequent cycles. It should be noted that the heterogeneous $\mathrm{Rh} / \mathrm{TPDB}$ catalyst can be used repeatedly, and its activity remains nearly constant after Cycle 2 (Table 1).

The temperature effects on the hydroformylation in the presence of $\mathrm{Rh} / \mathrm{TPDB}$ were evaluated based on the catalyst reuse data (Fig. 4a). At $60^{\circ} \mathrm{C}$, the aldehyde conversion rate does not exceed $34 \%$, the octene-1 conversion reaches about $50 \%$, and the $n /$ iso ratio is 1.8 . However, raising the temperature to $80^{\circ} \mathrm{C}$ boosts the aldehyde yield to $57 \%$ (with $n /$ iso $=1.4$ and $98 \%$ octene- 1 conversion). At $100^{\circ} \mathrm{C}$, despite a slight increase in the aldehyde yield (to $61 \%$ ), the $n /$ iso ratio declines to 0.6 as 

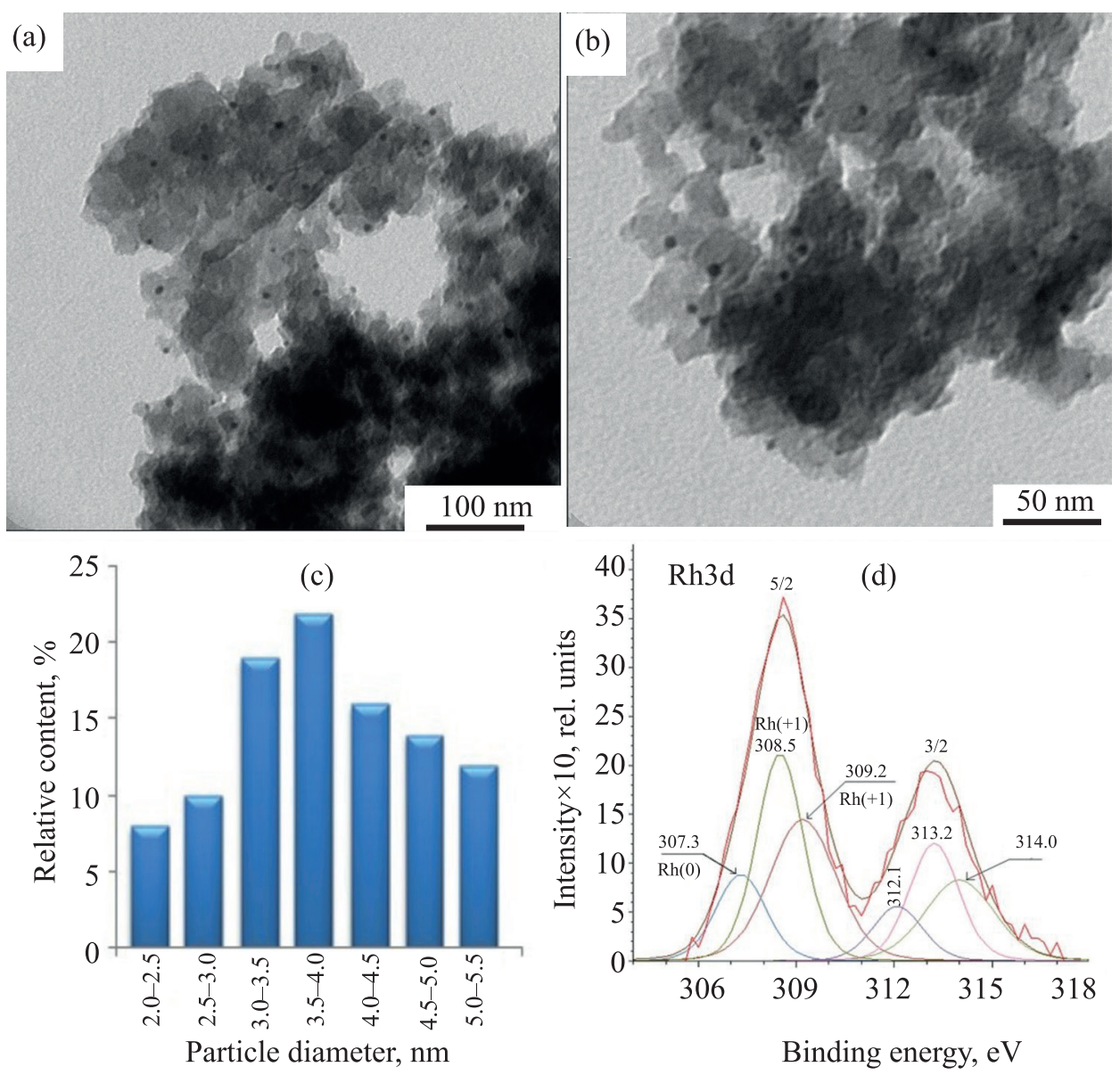

Fig. 3. (a, b) Micrographs; (c) particle size distribution; and (d) Rh3d core level X-ray photoelectron spectrum of the Rh/TPDB catalyst.

a result of the accelerated iso-octene hydroformylation. The highest $n /$ iso ratio (with yields being similar in all the cases compared) was achieved at $80^{\circ} \mathrm{C}$. This temperature also corresponds to the lowest amount of by-products.

The evaluation of the substrate conversion rate and of the accumulation of the products of octene-1 hydroformylation in the presence of Rh/TPDB (Fig. 4b), revealed that the octene- 1 conversion into aldehydes starts about $80 \mathrm{~min}$ after the experiment initiation. This is probably explained by the stabilization of diffusion processes in the system and the generation of the catalyst's active form. The substrate undergoes an almost complete (98\%) conversion within $300 \mathrm{~min}$, where the initial reaction step mostly promotes the substrate isomerization. The iso-octene content in the reaction mixture reaches its maximum after about 200 min from the experiment initiation, followed by a decline as a result of hydroformylation into iso-aldehydes.

Thus, based on the data on the catalytic activity and the physicochemical properties of the Rh/TPDB catalyst,

Table 1. Hydroformylation of octene-1 in presence of $\mathrm{Rh} / \mathrm{TPDB}$

\begin{tabular}{c|c|c|c|c}
\hline Cycle no. & Conversion, \% & Yield of $i$ so-octenes, \% & Yield of aldehydes, \% & $\begin{array}{c}\text { n/iso (yield ratio of } n \text {-aldehydes } \\
\text { to } \text { iso-aldehydes) }\end{array}$ \\
\hline 1 & 99 & 25 & 74 & 0.8 \\
2 & 99 & 42 & 57 & 1.4 \\
3 & 72 & 44 & 28 & 2.5 \\
4 & 77 & 48 & 29 & 2.6 \\
5 & 73 & 39 & 25 & 2.6 \\
6 & 64 & & 25 & 2.6 \\
\hline
\end{tabular}


(a)

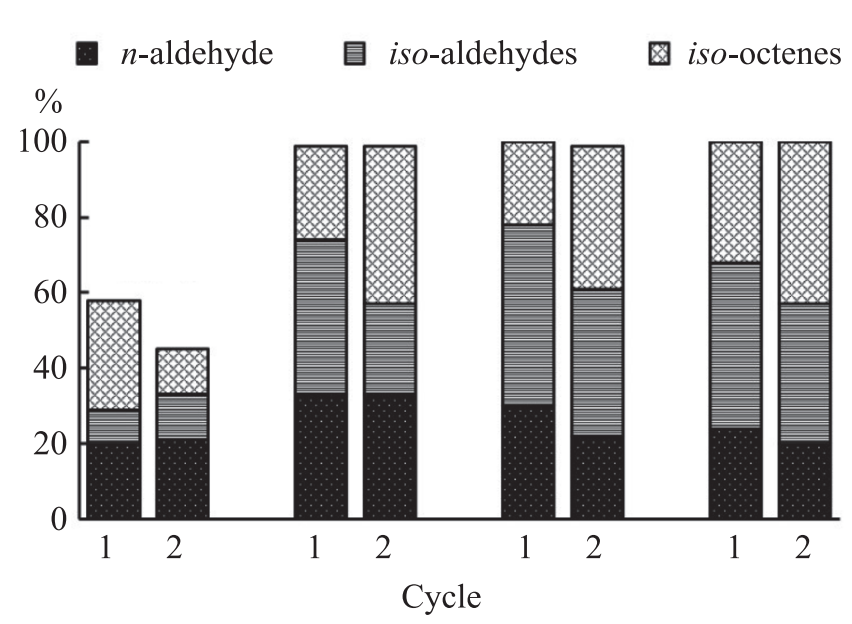

(b)

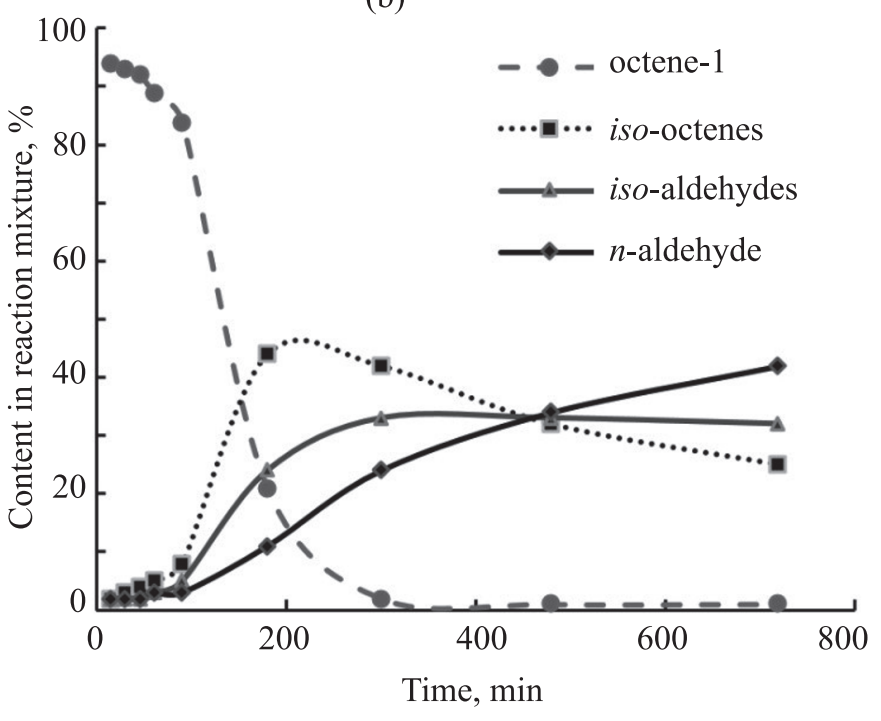

Fig. 4. Hydroformylation of octene- 1 in presence of $\mathrm{Rh} / \mathrm{TPDB}$. Reaction conditions: $\mathrm{Rh} /$ substrate $=1: 543 ; 2.0 \mathrm{MPa}\left(\mathrm{CO} / \mathrm{H}_{2}\right)$.

an assumption of its most likely structure was suggested (Fig. 5).

Rhodium nanoparticles can be stabilized by the $\pi$-system of aromatic polymer fragments and by heteroatoms and, thus, firmly fixed in the pores. In this case, the substrate may gain access to the "facets" of nanoparticles protruding onto the polymer surface, and these facets rather effectively catalyze isomerization of octene-1 (a side reaction). This assumption is further confirmed by the findings of the catalytic experiments. First, the sustaining catalytic activity in the reuse cycles

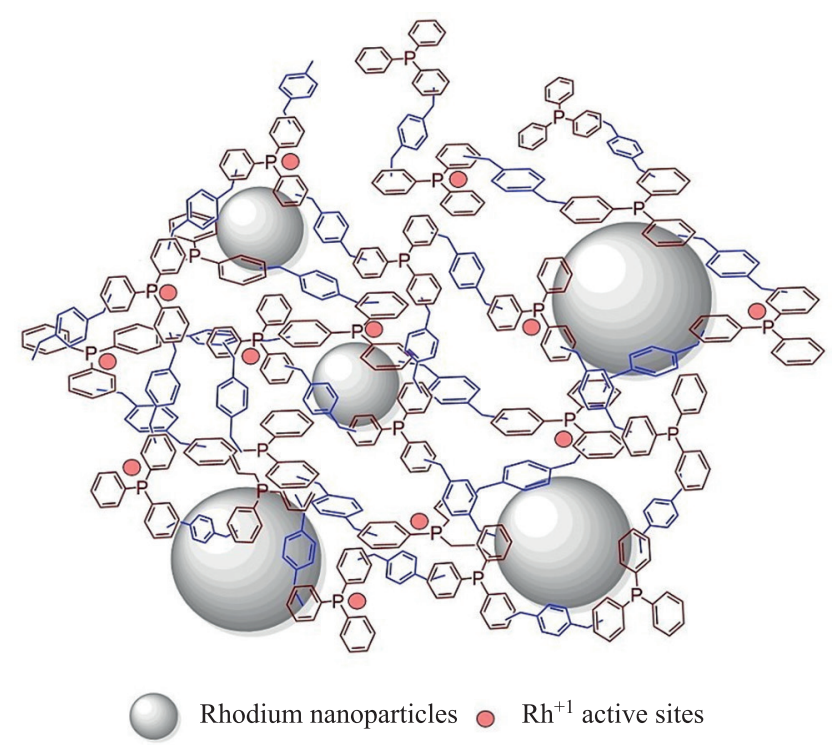

Fig. 5. Assumed structure of heterogeneous Rh/TPDB catalyst. proves that the active sites are firmly fixed on the support. Second, the substrate-related parameters (conversion rate, isomerization degree, and relative isomerization rate), the aldehyde yield, and the n/iso ratio deviate, to some extent, from the values that would be expected if the active sites consisted only of rhodium-phosphine complexes. Although $n /$ iso reaches 2.5-2.6 during the reuse of $\mathrm{Rh} / \mathrm{TPDB}$, the final product mixture $(5 \mathrm{~h}$, aldehyde yield ca. 30\%) contains a significant amount of iso-octenes. This leads us to expect the $n /$ iso ratio to be about $0.8-1.0$ when unsaturated compounds are fully converted into aldehydes. In our case, iso-octenes mostly remain in the reaction mixture, and the low rate of their hydroformylation may stem from local steric hindrances near the active sites of the catalyst. The catalytic conversions mostly occur on nanoparticles protruding onto the catalyst surface. At $80^{\circ} \mathrm{C}$, the turnover frequency (TOF) of octene-1 hydroformylation, on the basis of aldehydes produced, is about $100 \mathrm{~h}^{-1}$ (at $50 \%$ substrate conversion). This is quite consistent with the values of the same parameter reported for other heterogeneous catalysts [18]. The relatively low TOF of the reaction in the presence of $\mathrm{Rh} / \mathrm{TPDB}$ can be explained by the fact that the rhodium concentration on the surface is lower than its total concentration in the catalyst sample.

Thus, the catalyst under study exhibits sufficiently high activity in hydroformylation of octene-1, and the findings obtained from the examination of its structure suggest that its catalytic effect is associated both with the 
$\mathrm{Rh}(+1)$ complexes fixed on the polymer surface and with the $\mathrm{Rh}(0)$ nanoparticles stabilized in the pores.

\section{AUTHOR CONTRIBUTION}

D.N. Gorbunov, Yu.S. Kardasheva, and E.A. Karakhanov developed the concept of the study, adapted a method for synthesis of polymer support to the research task, and proposed the method for heterogeneous catalyst synthesis and a set of methods for its physicochemical examination. M.V. Nenasheva and R.P. Matsukevich synthesized and isolated the polymer and polymer-based catalyst samples. M.V. Terenina and D.N. Gorbunov analyzed the data obtained by IR spectroscopy, solid-state NMR, XPS, atomic absorption spectroscopy, TEM, and low-temperature nitrogen adsorption/desorption. M.V. Nenasheva and R.P. Matsukevich carried out the catalytic experiments on hydroformylation of octene- 1 in pressure reactors, interpreted the chromatography data on the product mixtures, and compiled the tables summarizing the main findings. D.N. Gorbunov and Yu.S. Kardasheva wrote the text part of the paper. All the authors participated in the discussion of the results. M.V. Nenasheva and D.N. Gorbunov prepared the graphic part for publication.

\section{AUTHOR INFORMATION} 8957

D.N. Gorbunov, ORCID: http://orcid.org/0000-0002-1603-

M.V. Nenasheva, ORCID: http://orcid.org/0000-00020770-8277

R.P. Matsukevich, ORCID: http://orcid.org/0000-00034333-6172 9786

M.V. Terenina, ORCID: http://orcid.org/0000-0002-4336-

Yu.S. Kardasheva, ORCID: http://orcid.org/0000-00026580-1082

E.A. Karakhanov, ORCID: http://orcid.org/0000-00034727-954X

\section{FUNDING}

This research was performed according to the Development program of the Interdisciplinary Scientific and Educational School of Lomonosov Moscow State University "The future of the planet and global environmental change."

\section{CONFLICT OF INTEREST}

E.A. Karakhanov, a co-author, is an editorial board member for the Journal Nanogeterogenny Kataliz (Nanoheterogeneous Catalysis). The other co-authors declare no conflict of interest requiring disclosure in this article.

\section{OPEN ACCESS}

This article is licensed under a Creative Commons Attribution 4.0 International License, which permits use, sharing, adaptation, distribution and reproduction in any medium or format, as long as you give appropriate credit to the original author(s) and the source, provide a link to the Creative Commons license, and indicate if changes were made. The images or other third party material in this article are included in the article's Creative Commons license, unless indicated otherwise in a credit line to the material. If material is not included in the article's Creative Commons license and your intended use is not permitted by statutory regulation or exceeds the permitted use, you will need to obtain permission directly from the copyright holder. To view a copy of this license, visit http://creativecommons.org/licenses/by/4.0/.

\section{REFERENCES}

1. Frank, R., Selent, D., and Börner, A., Chem. Rev., 2012, vol. 112, no. 11, pp. 5675-5732.

https://doi.org/10.1021/cr3001803

2. Rhodium Catalyzed Hydroformylation, van Leeuwen P.W.N.M. and Claver, C., Eds., Kluwer. Academic Publishers: Dordrecht, Netherlands., 2000, pp. 203-226. https://doi.org/10.1002/aoc.170

3. Gorbunov, D.N., Volkov, A.V., Kardasheva, Y.S., Maksimov, A.L., and Karakhanov, E.A., Petrol. Chem., 2015 , vol. 55 , pp. 587-603. https://doi.org/10.1134/S0965544115080046

4. Cole-Hamilton, D.J., Science, 2003, vol. 299, no. 5613, pp. 1702-1706.

https://doi.org/10.1126/science.1081881

5. van Leeuwen, P.W.N.M., Appl. Catal. A: Gen., 2001, vol. 212, nos. 1-2, pp. 61-81.

https://doi.org/10.1016/S0926-860X(00)00844-9

6. Dreimann, J.M., Kohls, E., Warmeling, H.F.W., Stein, M., Guo, L.F., Garland, M., Dinh, T.N., and Vorholt, A.J., ACS Catal., 2019, vol. 9, no. 5, pp. 4308-4319. https://doi.org/10.1021/acscatal.8b05066

7. Börner, A. and Franke, R., Hydroformylation: Fundamentals, Processes, and Applications in Organic Synthesis, John Wiley \& Sons, 2016, pp. 677-692 https://doi.org/10.1002/9783527677931

8. Kohlpaintner, C.W., Fischer, R.W., and Cornils, B., Appl. Catal. A: Gen., 2001, vol. 221, pp. 219-225. https://doi.org/10.1016/S0926-860X(01)00791-8

9. Cornils, B. and Kuntz, E.G., J. Organomet. Chem., 1995, vol. 502, pp. 177-186.

https://doi.org/10.1016/0022-328X(95)05820-F

10. Matsinha, L.C., Siangwata, S., Smith, G.S., and Makhubela, B.C.E., Catal. Rev., 2019, vol. 61, no. 1, pp. 111-133. https://doi.org/10.1080/01614940.2018.1541781

11. Zhao, J., Yi, J., Yang, C., Wan, K., Duan, X., Tang, S., Fu, H., Zheng, X., Yuan, M., Li, R.,

PETROLEUM CHEMISTRY Vol. 61 No. 62021 
and Chen, H., Catal. Lett., 2020.

https://doi.org/10.1007/s10562-020-03385-812

12. Obrecht, L., Kamer, P.C.J., and Laan, W., Catal. Sci. Technol., 2013, vol. 3, pp. 541-551. https://doi.org/10.1039/C2CY20538F

13. Warmeling, H., Koske, R., and Vorholt, A.J., Chem. Eng. Technol., 2017, vol. 40, no. 1, pp. 186-195. https://doi.org/10.1002/ceat.201600383

14. Hanf, S., Rupflin, L.A., Gläser, R., and Schunk, S.A., Catalysts, 2020, vol. 10, no. 5, ID 510. https://doi.org/10.3390/catal10050510

15. Luo, L., Li, H., Peng, Y., Feng, C., and Zeng, J., ChemNanoMat., 2018, vol. 4, no. 5, pp. 451-466. https://doi.org/10.1002/cnma.201800033

16. Chen, F., Jiang, X., Zhang, L., Lang, R., and Qiao, B., Chin. J. Catal., 2018, vol. 39, no. 5, pp. 893-898. https://doi.org/10.1016/S1872-2067(18)63047-5

17. Li, C., Wang, W., Yan, L., and Ding, Y., Front. Chem. Sci. Eng., 2018, vol. 12, pp. 113-123. https://doi.org/10.1007/s11705-017-1672-9

18. Gorbunov, D., Safronova, D., Kardasheva, Yu., Maximov, A., Rosenberg, E., and Karakhanov, E., ACS Appl. Mater. Interfaces, 2018, vol. 10, no. 31, pp. 26566-26575. https://doi.org/10.1021/acsami.8b02797

19. Zhao, J., He, Y., Wang, F., Zheng, W., Huo, C., Liu, X., Jiao, H., Yang, Y., Li, Y., and Wen, X., ACS Catal., 2020, vol. 10, pp. 914-920. https://doi.org/10.1021/acscatal.9b03228

20. Zhuchkov, D.P., Nenasheva, M.V., Terenina, M.V., Kardasheva, Yu.S., Gorbunov, D.N., and Karakhanov, E.A., Petrol. Chem., 2021, vol. 61, no. 1, pp. 1-14. https://doi.org/10.1134/S0965544121010011
21. Chen, L., Tian, J., Song, H., Gao, Z., Wei, H.W., and Wangab, W., RSC Adv., 2020, vol. 10, pp. 34381-34386. https://doi.org/10.1039/D0RA06515C

22. Varshavskii, Yu.S. and Cherkasova, T.G., Zh. Neorg. Khim., 1967, no. 12, pp. 1709-1711.

23. Wu, S., Teng, C., Cai, S., Jiang, B., Wang, Y., Meng, H., and Tao, H., Nanoscale Res. Lett., 2017, vol. 12, no. 1, ID 609 . https://doi.org/10.1186/s11671-017-2376-2

24. Hedman, J., Klasson, M., Nilsson, R., Nordling, C., Sorokina, M.F., Kljushnikov, O.I., Nemnonov, S.A., Trapeznikov, V.A., and Zyryanov, V.G., Physica Scripta, 1971, vol. 4, nos. 4-5, pp. 195-201. https://doi.org/10.1088/0031-8949/4/4-5/008

25. Standfest-Hauser, C.M., Lummerstorfer, T., Schmid, R., Hoffmann, H., Kirchner, K., Puchberger, M., Trzeciak, A.M., Mieczyńska, E., Tylus, W., and Ziółkowski, J.J., J. Mol. Catal. A: Chem., 2004, vol. 210, nos. 1-2, pp. 179-187. https://doi.org/10.1016/j.molcata.2003.09.012

26. Bellamy, L.J., $X=Y$ Bonds Other than Carbonyl $v S=O$, $N=O, P=O, P=S, C=S$ and $C=S e$ Vibrations, in The Infrared Spectra of Complex Molecules, Dordrecht: Springer, 1980, pp. 195-220. https://doi.org/10.1007/978-94-011-6520-4_6

27. Sitarz, M., Handke, M., and Mozgawa, W., Spectrochim. Acta, Part A, 2000, vol. 56, no. 9, pp. 1819-1823. https://doi.org/10.1016/S1386-1425(00)00241-9

28. Peng, Q., Yang, Y., and Yuan, Y., J. Mol. Catal. A: Chem., 2004, vol. 219, no. 1, pp. 175-181. https://doi.org/10.1016/j.molcata.2004.05.003 